\title{
Erratum
}

\section{Erratum to "Electrodeposition and Corrosion Protection Performance of Polypyrrole Composites on Aluminum [Int. J. Electrochem. Sci., 11 (2016) 3938 - 3951]"}

\author{
Mahmoud A. Hussein", Salih S. Al-Juaid, Bahaa M. Abu-Zied, Abou-Elhagag A. Hermas ${ }^{*}$ \\ Chemistry Department, Faculty of Science, King Abdulaziz University, Jeddah 21589, Saudi Arabia \\ *E-mail: mahussein74@yahoo.com, hagag_99@yahoo.com
}

Received: 31 May 2016 / Accepted: 3 May 2016 / Published: 7 July 2016

This is an erratum regarding the published article (Int. J. Electrochem. Sci., 11 (2016) 3938 - 3951), which has a mistake in the ACKNOWLEDGMENTS part.

The acknowledgments part was mistakenly assigned in the paper and the correct acknowledgments should be: This project was funded by Deanship of Scientific Research (DSR) at King Abdulaziz University, Jeddah, under grant no. S-13-354-1432. The authors, therefore, acknowledge with thanks DSR for technical and financial support.

This was not noticed at the time by the authors and it is corrected by this erratum now, and we apologize for any inconvenience this may cause.

The correct paragraph is as follows:

\section{ACKNOWLEDGMENTS}

This project was funded by Deanship of Scientific Research (DSR) at King Abdulaziz University, Jeddah, under grant no. S-13-354-1432. The authors, therefore, acknowledge with thanks DSR for technical and financial support.

(C) 2016 The Author. Published by ESG (www.electrochemsci.org). This article is an open access article distributed under the terms and conditions of the Creative Commons Attribution license (http://creativecommons.org/licenses/by/4.0/). 